\title{
Chitosan-based nanoparticles for survivin targeted siRNA delivery in breast tumor therapy and preventing its metastasis
}

This article was published in the following Dove Press journal:

International Journal of Nanomedicine

27 September 2016

Number of times this article has been viewed

\author{
Ping Sun ${ }^{1,2}$ \\ Wei Huang ${ }^{1,2}$ \\ Mingji Jin ${ }^{1,2}$ \\ Qiming Wang ${ }^{1,2}$ \\ Bo Fan ${ }^{1,2}$ \\ Lin Kang ${ }^{1,2}$ \\ Zhonggao Gao ${ }^{1,2}$
}

'State Key Laboratory of Bioactive Substance and Function of Natural Medicines, ${ }^{2}$ Department of Pharmaceutics, Institute of Materia Medica, Chinese Academy of Medical Sciences and Peking Union Medical College, Beijing, People's Republic of China
Correspondence: Zhonggao Gao Department of Pharmaceutics, Institute of Materia Medica, Chinese Academy of Medical Sciences, I Xian Nong Tan Street, Beijing 100050, People's Republic of China

Tel/fax +861063028096

Email zggao@imm.ac.cn

\begin{abstract}
Nanoparticle-mediated small interfering RNA (siRNA) delivery is a promising therapeutic strategy in various cancers. However, it is difficult to deliver degradative siRNA to tumor tissue, and thus a safe and efficient vector for siRNA delivery is essential for cancer therapy. In this study, poly(ethylene glycol)-modified chitosan (PEG-CS) was synthesized successfully for delivering nucleic acid drug. We deemed that PEGylated CS could improve its solubility by forming a stable siRNA loaded in nanoparticles, and enhancing transfection efficiency of siRNA-loaded CS nanoparticles in cancer cell line. The research results showed that siRNA loaded in PEGylated CS (PEG-CS/siRNA) nanoparticles with smaller particle size had superior structural stability in the physical environment compared to CS nanoparticles. The data of in vitro antitumor activity revealed that 4T1 tumor cell growth was significantly inhibited and cellular uptake of PEG-CS/siRNA nanoparticles in 4T1 cells was dramatically enhanced compared to naked siRNA groups. The results from flow cytometry and confocal laser scanning microscopy showed that PEG-CS/siRNA nanoparticles were more easily taken up than naked siRNA. Importantly, PEG-CS/siRNA nanoparticles significantly reduced the growth of xenograft tumors of 4T1 cells in vivo. It has been demonstrated that the PEG-CS is a safe and efficient vector for siRNA delivery, and it can effectively reduce tumor growth and prevent metastasis.
\end{abstract}

Keywords: PEGylated chitosan, non-viral vector, siRNA delivery, breast anti-tumor therapy

\section{Introduction}

Within the past few years, gene therapy had developed into a promising treatment strategy; it suppressed the expression of oncogene that caused cancer. ${ }^{1-3}$ In gene therapy, small interfering RNA (siRNA) has come into the spotlight; siRNA molecules consisting of 21-23 nucleotides can bind to target genes and degrade target messenger RNA with complementary sequences to produce a therapeutic effect. According to the literature, various cancers including cancers of the breasts, bladder, lungs, ovaries and prostate have been inhibited by siRNA in the recent years. ${ }^{4-9}$ Although the siRNA drug has preferable treatment effect, its clinical application faced many challenges; the major limitations of siRNA-based therapies include rapid degradation by nucleases and renal clearance following systemic administration, which leads to the therapy effect of siRNA decreasing greatly. In addition, low intracellular uptake and limited stability in the blood stream also restricted the application of siRNA. Since the instability and the lack of efficiency of naked siRNA have been demonstrated, it is necessary to develop the safety and effective carriers for siRNA-based therapeutics in cancer that can efficiently deliver the siRNA molecules to tumor cells. ${ }^{10-12}$ 
Recently, a lot of siRNA delivery carriers have been reported, including viral carriers, non-viral carriers, and cationic materials. ${ }^{13-15}$ The viral carriers are limited by their lower cargo loading capacity and safety problems related to immune reactions. ${ }^{16}$ In this context, non-viral carriers have gained more attention in siRNA delivery for cancer therapy; several non-viral vectors, including cationic lipids, gold nanoparticles, phosphatidylethanolamine, silica nanoparticles, polyethylenimine, polypeptides, poly(lactideco-glycolide), and chitosan (CS) have been successfully investigated for siRNA delivery. ${ }^{16-20}$

CS is a common non-viral vector for siRNA delivery. CS as siRNA delivery carrier has many advantages such as it is nontoxic, nonimmunogenic, biodegradable, and biocompatible..$^{21} \mathrm{CS}$ with positive charges under slightly acidic conditions allowed for electrostatic interactions with siRNA (negatively charged) to form nanoparticles or complexes, so CS had been widely used for siRNA delivery in the recent years. However, CS as siRNA delivery carrier has its limitations; one of the major limitations of CS is its low water solubility at physiological $\mathrm{pH}$ that attributes to the partial protonation of the amino group on the CS molecule; this can affect nucleic acid-binding capability and therefore can influence the stability of the nanoparticles in the blood stream, and ultimately cause the biological activity of the siRNA to decrease. Blood ingredients can destabilize the CS nanoparticles or complexes. For example, a part of serum proteins can cause nanoparticle or complexes aggregation, leading to vascular embolization and increased toxicity; or blood components with a negative charge can replace siRNA to combine with cationic carrier, ${ }^{22,23}$ leading to collapse of nanoparticles and siRNA release in the blood stream, followed by nucleases degradation and eventual decrease in the curative effect of siRNA. To increase solubility and stability to CS nanoparticles, poly(ethylene glycol) (PEG) grafting onto CS has been described; PEGylated CS for siRNA delivery has been widely reported in the past decade. PEG is a hydrophilic polymer that has been reported to enhance CS solubility and increase stability of the CS nanoparticle in the biological environment, and exerted a positive influence on the transfection efficiency. Characteristic properties of PEG are its formal electrostatic neutrality and unique hydration ability, allowing the formation of a compact hydration layer and reducing the protein surface interaction. According to the literature, a PEG density of $>7 \%$ is necessary for higher shielding against unspecific interactions with proteins and cells, leading to a steric stabilization effect. ${ }^{24,25}$

In this study, the PEG molecule was coupled on the hydroxyl of CS for preparing stable siRNA-loading nanoparticles with higher transfection efficiency via enhancing the solubility of CS. The substitution of PEG on the CS was controlled without the influence of the complexation ability of CS with siRNA; poly(ethylene glycol)-modified chitosan (PEG-CS)-based nanoparticles with a smaller particle size and a higher transfection efficiency could effectively delivery siRNA in vivo.

\section{Materials and methods \\ Materials, cell culture, and animals}

CS (degree of deacetylation $80 \%$ ) was obtained from Zhejiang Golden Shell Pharmaceutical Co., Ltd (Zhejiang, People's Republic of China). PEG was obtained from Laysan Bio, Inc. (Laysan, Arab, AL, USA), and siRNA was purchased from Suzhou GenePharma Co., Ltd (Suzhou, People's Republic of China). Carbodiimide hydrochloride and 1-hydroxybenzotriazole monohydrate were purchased from Aladdin Company (Shanghai, People's Republic of China). Phthalic anhydride (PA) and hydrazine monohydrate were obtained from J\&K Scientific Ltd (Beijing, People's Republic of China), and 5-diphenyltetrazolium bromide (MTT) was purchased from Sigma Aldrich (St Louis, MO, USA). Annexin V-FITC/PI apoptosis detection kit was obtained from the KeyGen Biotech (Nanjing, People's Republic of China). Fetal bovine serum (FBS), Roswell Park Memorial Institute-1640 medium, $0.25 \%$ trypsin, and phosphate buffered saline (PBS) were all purchased from Thermo Fisher Scientific Inc (Waltham, MA, USA), and other reagents, which were of analytical grade, were purchased from Beijing Chemical Reagents Co (Beijing, People's Republic of China). Live/Dead ${ }^{\circledR}$ viability/cytotoxicity kit was purchased from Bo Yao Biological Technology Co., Ltd (Shanghai, People's Republic of China).

4T1 cells were purchased from the Department of Pathology in the Institute of Medicinal Biotechnology at Peking Union Medical College, and were maintained in Roswell Park Memorial Institute-1640 medium containing $10 \%$ FBS. $4 \mathrm{~T} 1$ cells were incubated at $37^{\circ} \mathrm{C}$ in the carbon dioxide $\left(\mathrm{CO}_{2}\right)$ incubator. In this study, $4 \mathrm{~T} 1$ cells in logarithmic growth stage were carried out in all cell experiments.

Female BALB/c mice (4-6 weeks old) were purchased from the Laboratory Animals Center of Vital River (Beijing, People's Republic of China), and the mice were housed in a specified chamber with regular temperature $\left(22 \pm 2^{\circ} \mathrm{C}\right)$ and relative humidity $(40 \%-60 \%)$. The overall study of this project including the part of animal study has been approved by the Institute of Materia Medica in Chinese Academy of Medical Sciences (CAMS) and Peking Union Medical College (PUMC). Also, all animal experiments were approved by the Laboratory Animal Ethics Committee in the Institute 
of Materia Medica in CAMS and PUMC, and the operational procedures of animal experiments abided by national and institutional guidelines and protocols for the care and use of experiment animals.

\section{Synthesis of PEG-CS polymer}

Both $1.00 \mathrm{~g} \mathrm{CS}$ and $2.73 \mathrm{~g}$ PA were added to $20 \mathrm{~mL} \mathrm{N,N-}$ dimethylformamide (DMF) solution, under nitrogen atmosphere; the mixture of CS and PA was stirred for 8 hours at $110^{\circ} \mathrm{C}$ and phthaloyl anhydride-chitosan was obtained; it was dialyzed against for 2 days with 3,500 Da dialysis tube. Phthaloyl anhydride-chitosan $50 \mathrm{mg}$ was dissolved in $5 \mathrm{~mL}$ DMF solution; $6 \mathrm{mg}$ PEG, $3 \mathrm{mg}$ carbodiimide hydrochloride, and $2.0 \mathrm{mg} 1$-hydroxybenzotriazole were added to the above mentioned DMF solution; the reaction was stirred for 24 hours at room temperature to produce phthaloyl anhydride-PEGylated chitosan. During the last step of the synthesis, the amine groups of CS were deprotected using $50 \%(\mathrm{~V} / \mathrm{V})$ hydrazine monohydrate in DMF; the reaction was carried out at $100^{\circ} \mathrm{C}$ for 4 hours under nitrogen conditions. The reaction product was dialyzed in methanol and deionized water $(\mathrm{V} / \mathrm{V}=1: 1)$ solution for 2 days, and then was dialyzed in deionized water solution for 2 days. Following dialysis, the sample was freeze-dried for 24 hours, and the resultant product of PEG-CS copolymer was obtained; the synthetic route is shown in Figure $1 .^{26}$

\section{Characterization of PEG-CS polymer}

The PEG-CS polymer was characterized through proton nuclear magnetic resonance ( ${ }^{1} \mathrm{H}-\mathrm{NMR}$ ) (Mercury $500 \mathrm{MHz}$ NMR) and Fourier transform infrared spectroscopy (FTIR), respectively.

5 mg PEG-CS polymer was dissolved in deuterium oxide and clusters of deuterated acetic acid solvent. Chemical shifts $(\delta)$ were reported in ppm using tetramethylsilane as an internal reference.

For the FTIR experiment, firstly, the PEG-CS polymer was compressed into $\mathrm{KBr}$ flake, and then the samples were tested in the range of $600-4,000 \mathrm{~cm}^{-1}$ using a Nicolet 5700 FTIR spectrometer (Thermo, Thermo Electron Corporation, USA).

\section{Preparation and characterization of PEG-CS/siRNA nanoparticles}

The PEG-CS/siRNA nanoparticles were prepared by ionic gelation as described in the literature. ${ }^{27}$ First, PEG-CS were dissolved in acetic acid solution with the concentration of $1 \mathrm{mg} / \mathrm{mL}$, and then sterilized by $0.22 \mu \mathrm{m}$ filtered membranes.

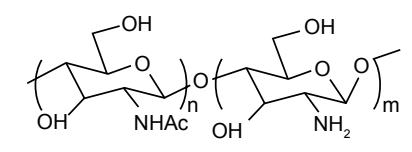

cs
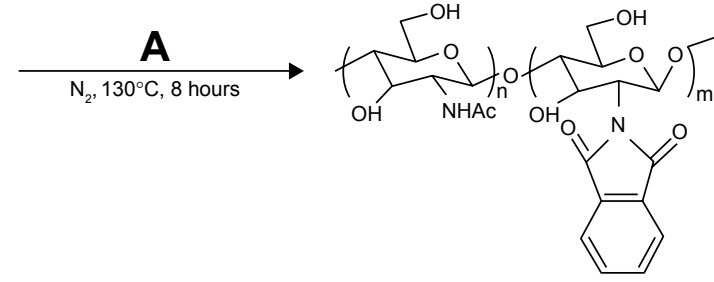

CS-PA
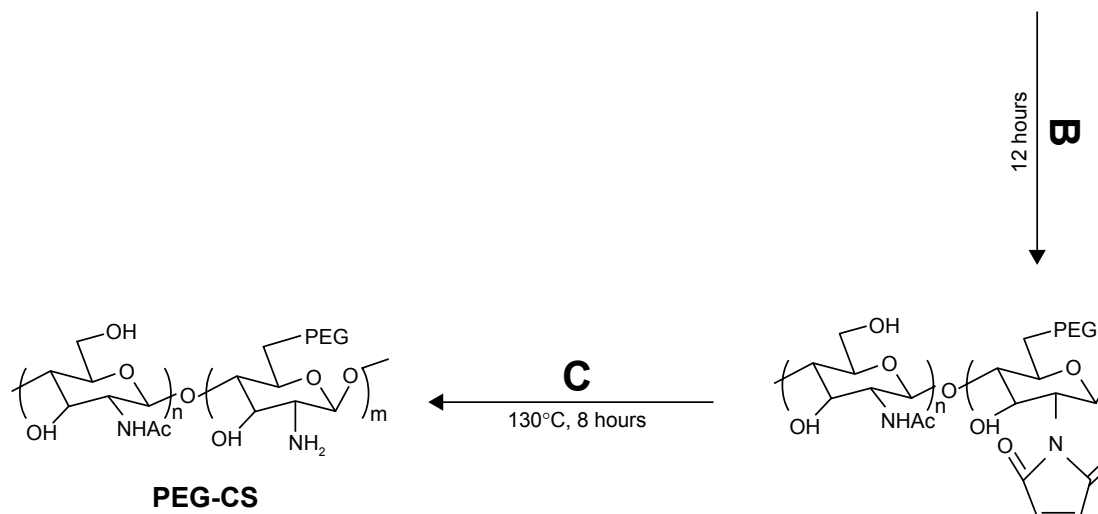

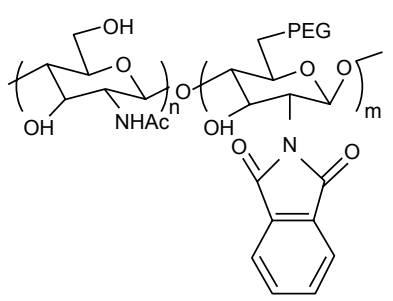

PA-PEG-CS

Figure I Synthetic routes of PEG-CS.

Notes: (A) PA, (B) EDC, HOBt, PEG, and (C) HM.

Abbreviations: CS, chitosan; EDC, carbodiimide hydrochloride; HM, hydrazine monohydrate; HOBt, I-hydroxybenzotriazole monohydrate; PA, phthalic anhydride; PA-CS, phthaloyl anhydride-chitosan; PA-PEG-CS, phthaloyl anhydride PEGylated chitosan; PEG, poly(ethylene glycol); PEG-CS, poly(ethylene glycol)-chitosan. 
siRNA $20 \mu \mathrm{M}$ siRNA solution was obtained by diluting siRNA with diethylpyrocarbonate water, and then equal volumes of PEG-CS and siRNA solution were preheated at $55^{\circ} \mathrm{C}$ water bath for 20 minutes, respectively. Subsequently, the mixture of PEG-CS and siRNA solution was vortexed immediately for 40 seconds, and PEG-CS/siRNA nanoparticles were generated. Particle size and zeta potential of PEG-CS/siRNA nanoparticles were analyzed through Malvern Zetasizer nano instruments (Malvern Instruments Ltd. Britain). The surface morphology of PEG-CS/siRNA nanoparticles was analyzed through the transmission electron microscopy.

\section{Gel retardation assay}

The gel retardation assay was selected to estimate the loading ability of the PEG-CS polymer to siRNA; the experiment was carried out in $4 \%$ agarose gel. First, the PEG-CS solution at weight ratios ranging from 60 to 200 was used to complex $1 \mu \mathrm{g}$ siRNA; the PEG-CS/siRNA nanoparticle solution was loaded onto agarose gel and subjected to electrophoresis in $1 \times$ Tris acetate-EDTA buffer (TAE) acetic acid buffer at $80 \mathrm{~V}$ for 45 minutes. Then, the agarose gel was stained in the ethidium bromide solution for 30 minutes. Finally, the ultraviolet gel imaging system (BIO-BEST 135A, SIM International Group Co., Ltd, Los Angeles, CA, USA) was used to analyze the loading capacity of PEG-CS polymer.

\section{Colloidal stability and serum stability of the PEG-CS/siRNA nanoparticles}

For estimating the colloidal stability of the PEG-CS/siRNA nanoparticles, the nanoparticles were incubated with FBS solution ( $\mathrm{v}: \mathrm{v}=1: 1)$ at $4{ }^{\circ} \mathrm{C}$. The average particle size of nanoparticles was tested at $0,1,3$, and 6 hours by Malvern Zetasizer nano instruments, respectively.

For the blood serum stability experiment, PEG-CS/ siRNA nanoparticles solution and naked siRNA solution were incubated in FBS solution ( $\mathrm{v}: \mathrm{v}=1: 1)$ at room temperature, respectively. Each sample was gathered at 1, 3, 6, and 12 hours, and analyzed by gel electrophoresis. Before gel electrophoresis, PEG-CS/siRNA nanoparticles solution was treated with heparin sodium salt solution for 30 minutes to replace siRNA from the nanoparticles.

\section{MTT assay}

The MTT assay was carried out to estimate the cytotoxicity of PEG-CS polymer and the antiproliferation effects of PEG-CS /siRNA nanoparticles.

4T1 tumor cells were seeded into a 96-well plate with a density of 5,000 cells/well, which were cultured 24 hours for attachment, $20 \mu \mathrm{L}$ PEG-CS polymer at various concentrations was added into a 96-well plate, and tumor cells with no PEG-CS polymer were used as the control group; the blank group was prepared by only adding culture medium. Six samples were selected for every experimental group to evaluate the cytotoxicity of PEG-CS polymer; after 48 hours of incubating, the optical density value was tested through the SpectraMax 190 Absorbance Microplate Reader (Bio Tek Instruments, Inc. USA) at $490 \mathrm{~nm}$.

Antiproliferation effects of PEG-CS/siRNA nanoparticles on 4T1 tumor cells were performed by MTT assay too; $4 \mathrm{~T} 1$ cells were seeded into a 96-well plate with a density of 5,000 cells/well for culturing for 24 hours and then $20 \mu \mathrm{L}$ of PEG-CS/siRNA nanoparticles solution containing 5 pmol siRNA was added to restrain tumor cell proliferation. The same dose of naked siRNA ( $5 \mathrm{pmol} /$ well) was used on the control group. Cells without treatment (only adding culture medium) were used as the blank group. Six samples were selected for every experimental group to evaluate the antiproliferation effect. After another 48 hours of culturing, $20 \mu \mathrm{L}$ of MTT reagent was added into each well for incubating for 4 hours, then the MTT solution was removed and $150 \mu \mathrm{L}$ DMSO was added in each well. Finally, optical density value was tested by the SpectraMax 190 Absorbance Microplate Reader.

To further investigate the inhibition effects of PEG-CS/ siRNA nanoparticles on tumor cells, Live/Dead ${ }^{\circledR}$ viability/ cytotoxicity test was performed; $5 \times 10^{4} 4 \mathrm{~T} 1$ tumor cells were seeded into a 12 -well plate for culturing for 24 hours. Subsequently, $50 \mu \mathrm{L}$ PEG-CS/siRNA nanoparticles suspension containing $50 \mathrm{pmol}$ siRNA and $1 \mathrm{~mL}$ serum-free medium was added into each well as the test groups, and the same dose of naked siRNA (50 pmol/well) was added to use as the negative group. The cells without any treatment was the control group. After 4 hours of transfection, the drug suspensions were removed and replaced with culture medium containing $10 \%$ FBS for another 44 hours of incubation. They were then washed twice with PBS, and $0.8 \mathrm{~mL}$ calcein acetoxymethyl and ethidium homodimer-1 working solution were added for incubating for 30 minutes at $37^{\circ} \mathrm{C}$. The results were observed by fluorescence microscope.

\section{Apoptosis assay}

$4 \mathrm{~T} 1$ cells were seeded into a 6-well plate with a density of $12 \times 10^{4}$ cells/well and cultured in a $\mathrm{CO}_{2}$ incubator for 24 hours. Subsequently, $100 \mu \mathrm{L}$ of PEG-CS/siRNA nanoparticles suspensions containing 100 pmol siRNA and $1.9 \mathrm{~mL}$ serum-free medium were added into each well as the test 
groups, and the same dose of naked siRNA (100 pmol/well) was added for use as the negative group. After 4 hours of transfection, the nanoparticles suspension was removed, and replaced with culture medium containing $10 \%$ FBS for another 44 hours of culturing. Cells in each well were then gathered and centrifuged, and washed twice with PBS. The collected cells were dispersed in $0.5 \mathrm{~mL}$ binding buffer. Subsequently, $5 \mu \mathrm{L}$ annexin V-FITC and $5 \mu \mathrm{L}$ propidium iodide were added into the above binding buffer solution. After 20 minutes of incubation, the treated cells were detected by flow cytometer immediately.

\section{Cellular uptake}

Cellular uptake of PEG-CS/siRNA-FAM (FAM-labeled siRNA) nanoparticles was quantified by flow cytometry; $10 \times 10^{4}$ cells/well were added into a 6 -well plate and cultured for 24 hours in $\mathrm{CO}_{2}$ incubator. They were then incubated with PEG-CS/siRNA-FAM nanoparticles and naked siRNA-FAM for 4 hours at a concentration of $100 \mathrm{pmol} /$ well. Subsequently, the cells were collected and resuspended in $0.5 \mathrm{~mL}$ PBS solution, and then the collected cells were detected by flow cytometer.

\section{Confocal laser scanning microscopy images}

The $3 \times 10^{4} 4 \mathrm{~T} 1$ tumor cells were plated into a 24 -well plate and allowed to attach for 24 hours in the $\mathrm{CO}_{2}$ incubator. The tumor cells were then washed with PBS solution twice. PEG-CS/siRNA-FAM nanoparticles were added into the 24-well plate for incubation for 4 hours. Subsequently, the $4 \mathrm{~T} 1$ cells were fixed in $4 \%$ formaldehyde for 10 minutes, and cell nuclei stained with 4',6-diamidino-2-phenylindole for 10 minutes. Images were then acquired using confocal fluorescence microscope (LSM 710, Carl Zeiss Shanghai Co., Ltd, Beijing Branch, People's Republic of China) with filters of $410-495 \mathrm{~nm}$.

\section{Animal experiments}

Tumor-bearing BALB/c mice were established by subcutaneous injection of $15 \times 10^{4} 4 \mathrm{~T} 1^{\text {luc }}$ cells into the fourth mammary location of 4-6-week-old female BALB/c mice. Mice were then randomly assigned to three groups after the tumor volume reached around $100 \mathrm{~mm}^{3}(\mathrm{n}=5)$ : saline (blank), free siRNA (negative control), PEG-CS/siRNA nanoparticles. Drug administration was performed five times with 2 days spaced between each administration; the injection quantity of siRNA was $0.3 \mathrm{mg}$ siRNA $/ \mathrm{kg}^{-1}$. Tumor volumes and body weights were recorded every other day, tumor volumes were calculated as $\left(S^{2} \times L\right) / 2$, where $S$ and $L$ represent the short and long diameter of tumors, respectively. All mice were sacrificed 4 days after the last administration, and the tumors were excised, weighed, photographed, and stored in $4 \%(\mathrm{w} / \mathrm{v})$ paraformaldehyde solution.

To effectively evaluate the inhibition effect of tumor metastasis of PEG-CS/siRNA nanoparticles, the phenomenon of tumor metastasis was observed in the early, middle, and late stage of administration by IVIS $^{\circledR}$ SPECTRUM CT (Caliper Life Sciences, Inc. NASDAQ:CALP) in vivo imaging system. After the last administration, the mice were executed by cervical dislocation and their lungs were collected. The lungs were immersed in picric acid solution for 18 hours and then fixed in 4\% (w/v) paraformaldehyde for 24 hours. The lung tissue sections were stained with hematoxylin and eosin, embedded into paraffin, and then cut into slices of $5 \mu \mathrm{m}$ thickness. The slices were then stained with hematoxylin and eosin and observed for tumor metastasis effect with light microscopy.

\section{Results and discussion Synthesis and structural characterization of PEG-CS}

CS is a polysaccharide, which is obtained from natural sources, and CS molecular carries positive charges after protonation of amine group in the acid environment. These positive charges can complex with the negatively charged nucleic acid molecules to form nanoparticles by electrostatic interaction. So CS is usually used as a safe and efficient vector for siRNA or DNA delivery. ${ }^{28}$ However, CS has lower solubility that leads to instability of CS nanoparticles in physiological conditions. In order to increase the solubility of CS and prepare stable CS nanoparticles, PEG was selectively grafted onto the hydroxyl groups of CS to produce PEG-CS copolymer. The reaction process of grafting to $\mathrm{CS}$ is easy. First, CS was interacted with PA to protect the amine groups at $110^{\circ} \mathrm{C}$ and nitrogen environment. Then the carboxyl groups of PEG were conjugated with the hydroxyl group of CS through a coupling reaction using carbodiimide hydrochloride and 1-hydroxybenzotriazole as coupling reagent. ${ }^{29}$ Finally, the amine groups of PEG-CS polymer were deprotected by hydrazine monohydrate/DMF (v/v 1:1) mixture; PEG-CS polymer was synthesized as siRNA delivery carrier.

The chemical structure of PEG-CS copolymers was confirmed by ${ }^{1} \mathrm{H}-\mathrm{NMR}$ (Figure 2) and FTIR (Figure 3 ) analysis. The ${ }^{1} \mathrm{H}-\mathrm{NMR}$ of PEG-CS spectrum was obtained in $0.5 \mathrm{~mL}$ deuterium oxide with $10 \mu \mathrm{L}$ clusters of deuterated acetic acid. 

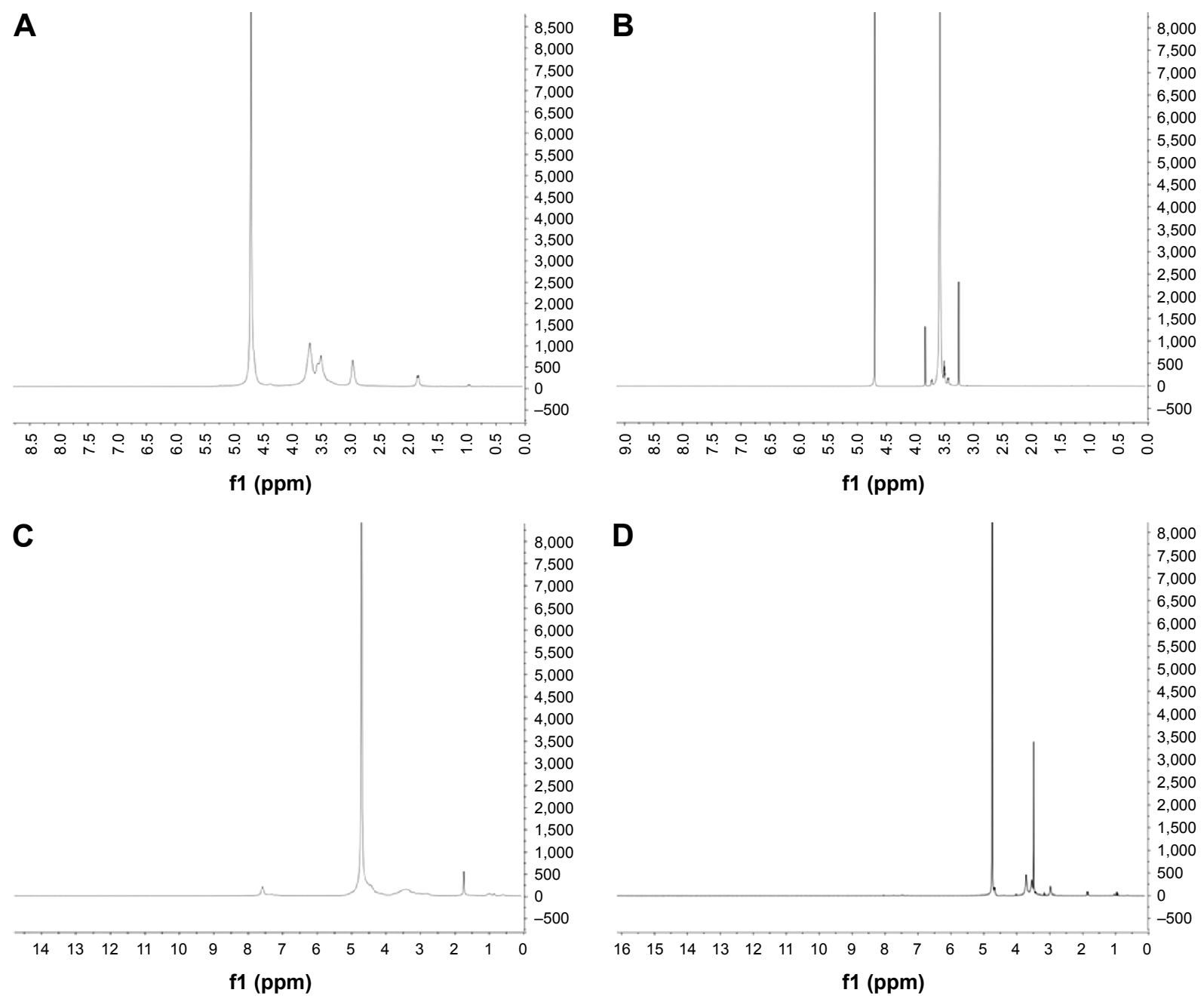

Figure 2 'H-NMR spectra of synthetic materials.

Notes: (A) CS, (B) PEG, (C) CS-PA, and (D) PEG-CS.

Abbreviations: CS, chitosan; CS-PA, chitosan-phthalic anhydride; PEG, polyethylene glycol; PEG-CS, poly(ethylene glycol)-chitosan.

The results of ${ }^{1} \mathrm{H}-\mathrm{NMR}$ are shown in Figure 2. It is clear that the 3.5-4.1 ppm was attributed to the $-\mathrm{CH}_{2}$ - in $\mathrm{CS}$ molecule (Figure 2A), and the 3.6 and $3.3 \mathrm{ppm}$ were attributed to the two $\mathrm{CH}_{2}$ and the terminal $\mathrm{CH}_{3}$ of PEG (Figure 2B). The chemical shift at $7.78 \mathrm{ppm}$ was attributed to the aromatic proton of the phthaloyl moiety (Figure 2C), which is present in the CS-PA spectrum but disappeared in PEG-CS spectrum (Figure 2D). In addition, the characteristic peak of PEG at $3.6 \mathrm{ppm}$ and the characteristic peak of CS at 3.5-4.2 ppm were observed in Figure 2D. The ${ }^{1} \mathrm{H}-\mathrm{NMR}$ analysis result verified that the PEG was successfully conjugated to the CS. ${ }^{30,31}$

The FTIR data in Figure 3 shows the characteristic absorption peak at 1,667 and $1,596 \mathrm{~cm}^{-1}$ belonging to the amides of $\mathrm{CS}$, and the $\mathrm{C}-\mathrm{O}$ stretching vibrations peaks of pyranose in CS molecules located at $1,150-1,000 \mathrm{~cm}^{-1}$ (Figure 3A). The spectrum of PEG had the characteristic peak at 3,446 and $1,733 \mathrm{~cm}^{-1}$, which corresponded to the stretching vibrations of hydroxyl $(-\mathrm{OH})$ and the stretching vibrations of carbonyl group $(\mathrm{C}=\mathrm{O})$ of carboxyl group, respectively. The peaks at 2,888 and $1,113 \mathrm{~cm}^{-1}$ refers to the stretching of the alkyl group $\left(-\mathrm{CH}_{2}\right)$ and stretching vibration of the ether group $(\mathrm{C}-\mathrm{O})$ in PEG, respectively (Figure 3B). The FTIR spectra in Figure 3C shows PEG-grafted CS, the characteristic peaks at 2,884 (C-H stretching) and 1,105 $\mathrm{cm}^{-1}$ (C-O stretching) belong to PEG. The peaks at 1,595 (amide II) and 1,150-1,000 $\mathrm{cm}^{-1}$ (pyranose) belong to CS. The results suggested that PEG was successfully conjugated to the CS..$^{32,33}$

\section{Preparation and characterization of PEG-CS/siRNA nanoparticles}

Figure 4A shows that nanoparticles were obtained with PEG-CS complexing siRNA. The mean diameter of PEG-CS/ siRNA nanoparticles was $100 \mathrm{~nm}$ with the size distribution being relatively narrow. The PEG was coupled on the hydroxyl of CS, so a lot of amino existed that make PEG-CS having a better complex ability, and can increase the stability 

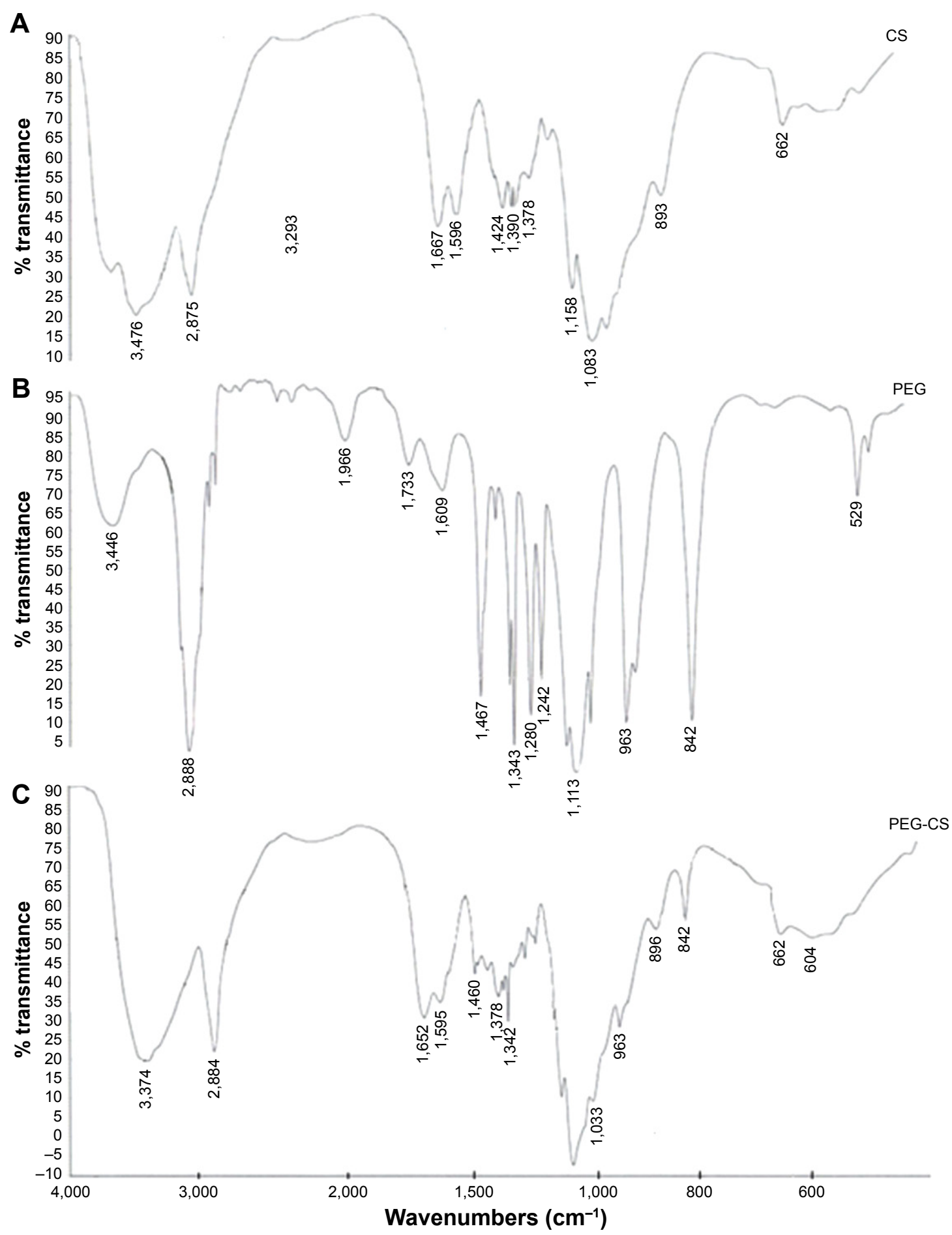

Figure 3 FTIR spectra of synthetic materials.

Notes: (A) CS, (B) PEG, and (C) PEG-CS.

Abbreviations: CS, chitosan; PEG, polyethylene glycol; PEG-CS, poly(ethylene glycol)-chitosan; FTIR, Fourier transform infrared spectroscopy.

of nanoparticles. PEG-CS/siRNA nanoparticles were analyzed by transmission electron microscopy, Figure 4B. It can be observed that nanoparticles with a smaller size are of spherical shape with a smooth surface. These results showed that PEG-CS/siRNA nanoparticles were successfully prepared.

\section{Gel retardation assay}

Gel retardation assay was used to estimate the encapsulating ability of the PEG-CS polymer to siRNA. In this study, we prepared different PEG-CS/siRNA nanoparticles at the weight ratios of 60:1, 80:1, 100:1, 120:1, 150:1, and 200:1. As shown in Figure 5, when the weight ratio of PEG-CS 
A

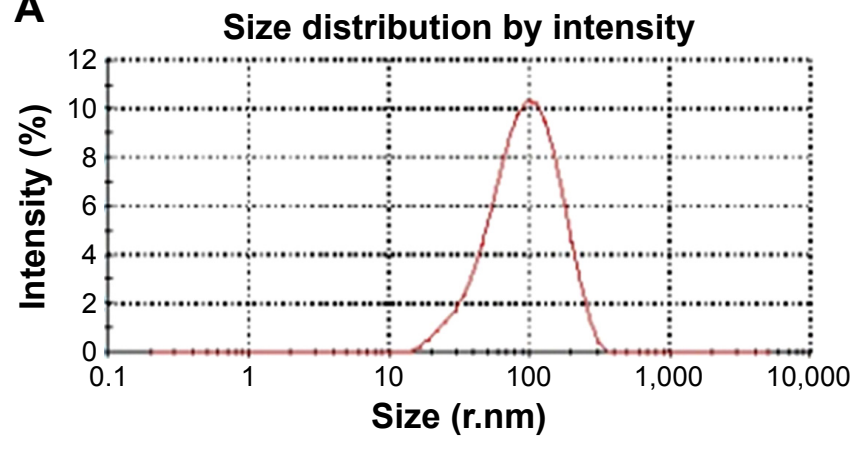

B

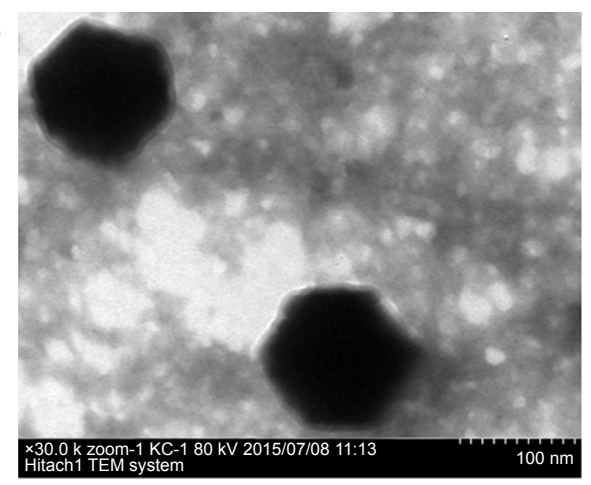

Figure 4 Chemicophysical characterization of PEG-CS/siRNA nanoparticles.

Notes: (A) Particle size distribution of PEG-CS/siRNA nanoparticles and (B) TEM image of PEG-CS/siRNA nanoparticles.

Abbreviations: PEG-CS, poly(ethylene glycol)-chitosan; siRNA, small interfering RNA; TEM, transmission electron microscope.

to siRNA was 100:1, the white band from siRNA disappeared. This result showed that PEG-CS as delivery carrier can condense siRNA efficiently, and siRNA could be completely loaded to PEG-CS polymer above the weight ratio of 100:1.

\section{Colloidal stability and serum stability of the PEG-CS/siRNA nanoparticles}

The colloidal instability hinders the application of CS nanoparticles in vivo. PEG-CS polymer as efficient siRNA delivery carrier was expected to stabilize the nanoparticle structure; PEG-CS/siRNA nanoparticles solution was incubated with the same volume of FBS at $4^{\circ} \mathrm{C}$ for $0,1,3$, and 6 hours.

\section{A $B$ C C D $E$ E}

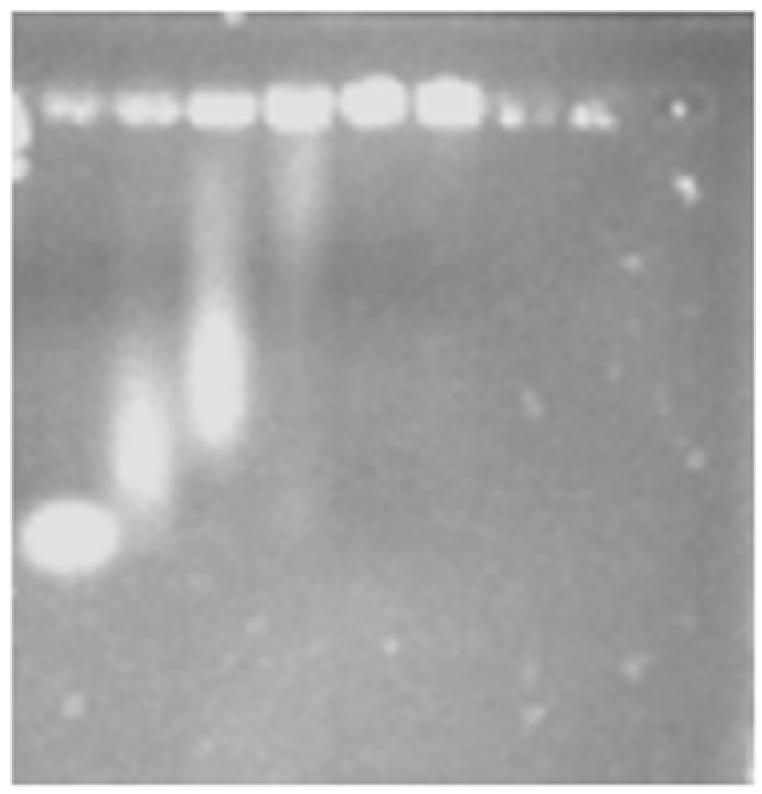

Figure 5 Gel retardation assay of PEG-CS/siRNA nanoparticles with different weight ratio of PEG-CS to siRNA.

Notes: (A) Naked siRNA, (B) 40:1, (C) 80:1, (D) 100:I, (E) I50:1, and (F) 200:1.

Abbreviations: PEG-CS, poly(ethylene glycol)-chitosan; siRNA, small interfering RNA.
The nanoparticles had consistent diameters of 100-200 nm after incubation for 6 hours (Figure 6A). Above results suggested that the PEG-CS/siRNA nanoparticle was stable in the PBS solution containing 50\% FBS.

Moreover, for evaluating the blood serum stability of PEG-CS polymer as siRNA delivery tool, we researched the blood serum stability of PEG-CS/siRNA nanoparticles in $50 \%$ FBS solution at room temperature through gel electrophoresis experiment. The research result in Figure 6B showed that PEG-CS polymer can protect siRNA from degradation for 12 hours, while naked siRNA rapidly degraded after incubating for 1 hour. Obviously, the PEG-CS polymer can efficiently protect siRNA from degrading serum-driven nucleases, and the high blood serum stability of nanoparticles may be ascribed to the PEG shell.

\section{MTT assay}

Cytotoxicity is a key issue in the biological application of siRNA delivery vector. Cytotoxicity may be related to factors such as its stabilizer, structure, and zeta potential. Here, an MTT test was used to estimate the cytotoxicity of PEG-CS polymer on 4T1 tumor cells. As shown in Figure 7A, less cytotoxicity was observed with increasing concentrations of PEG-CS polymer. The cell viability of PEG-CS polymer at high concentrations of 80 and $100 \mu \mathrm{g} / \mathrm{mL}$ was $94 \%$ and $95 \%$, respectively. Based on the above results, we may draw the conclusion that PEG-CS polymer has almost no cytotoxicity, which is a safe carrier for siRNA delivery.

In addition, cell viability after treating with culture medium, naked siRNA and PEG-CS/siRNA nanoparticles was studied in 4T1 cells using MTT assay. Results in Figure 7B show that PEG-CS/siRNA nanoparticles displayed lower cell viability compared with the naked siRNA group. The cell viability ratio of naked siRNA was $62 \%$, while the cell viability ratio of PEG-CS/siRNA nanoparticles was $48 \%$. 


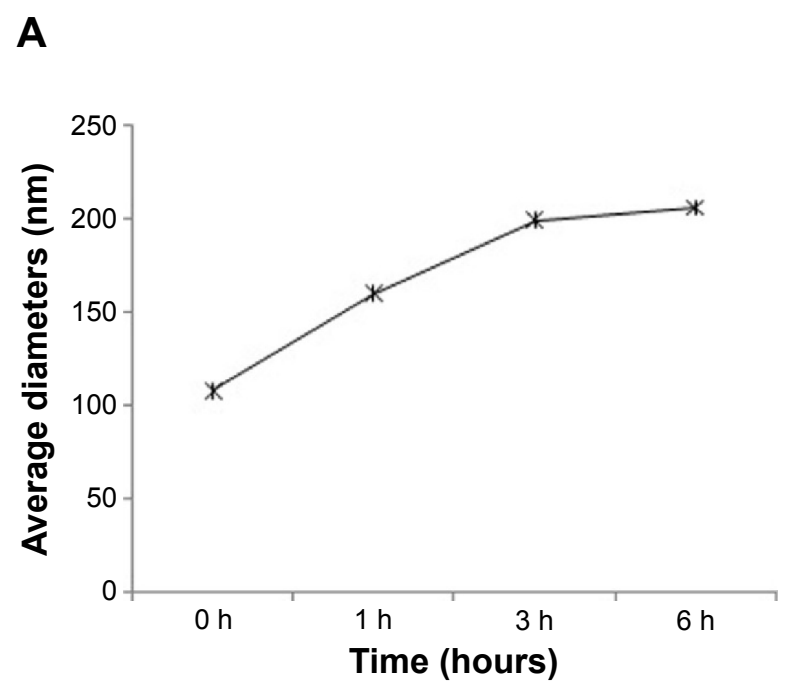

\section{B Incubation time (hours)}

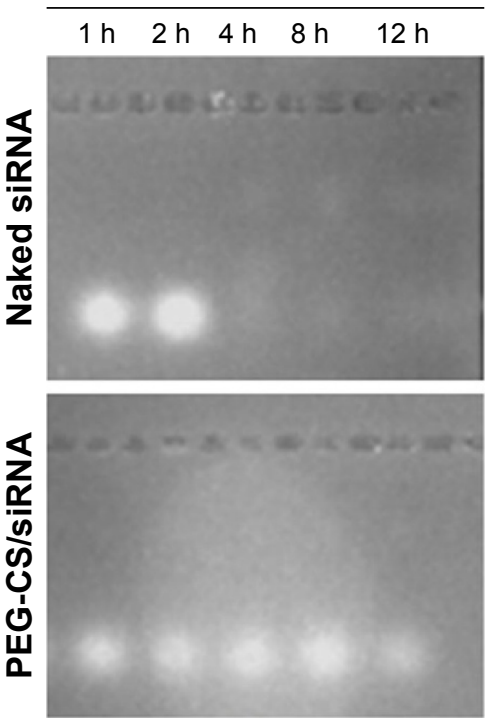

Figure 6 Stability of PEG-CS/siRNA nanoparticles.

Notes: (A) Changes in particle size of PEG-CS/siRNA nanoparticles. (B) Serum stability assay of naked siRNA and PEG-CS/siRNA nanoparticles at I, 2, 4, 8, and I2 hours. Abbreviations: PEG-CS, poly(ethylene glycol)-chitosan; siRNA, small interfering RNA.

In other words, PEG-CS/siRNA nanoparticles can inhibit the growth of the tumor cells effectively. Based on these results, we can draw the conclusion that PEG-CS/siRNA nanoparticles can have an obvious antiproliferation effect on tumor cells.
Live/Dead ${ }^{\circledR}$ viability/cytotoxicity test was carried out to estimate the inhibition effect on 4T1 tumor cells. Polyanionic dye calcein acetoxymethyl is well retained within live cells and produces an intense uniform green fluorescence in live cells, while ethidium homodimer-1 enters dead cells with
A

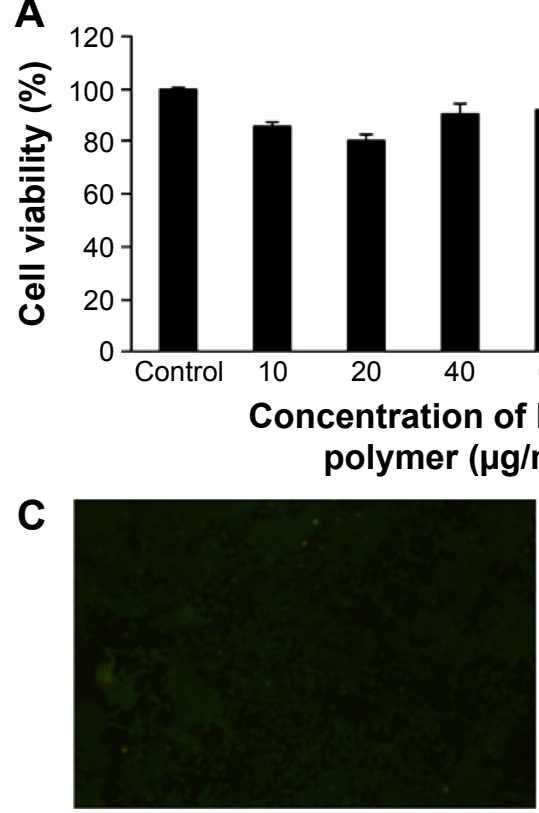

Blank
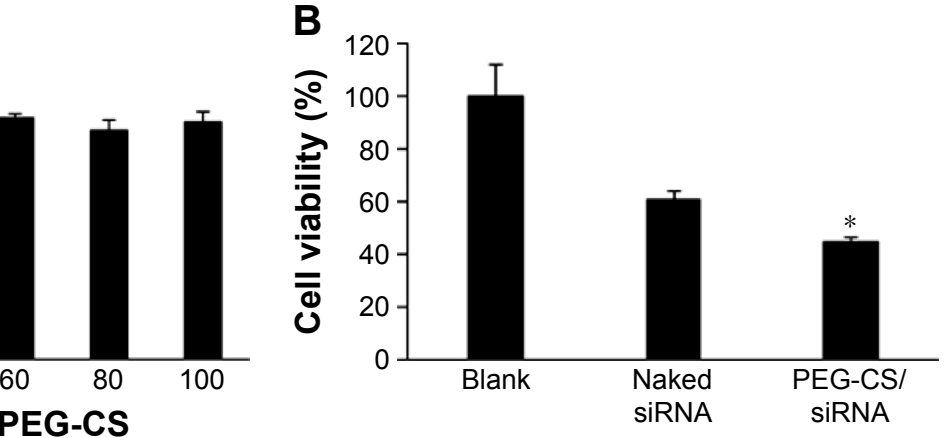

Figure 7 Cell viability of 4TI cells incubated with different concentrations of PEG-CS polymer, naked siRNA, and PEG-CS/siRNA nanoparticles.

Notes: (A) Viability of 4TI cells after incubating with different concentrations of PEG-CS polymer for 48 hours, $n=6$. (B) Cell viability of 4 TI cells after incubating with PEG-CS/siRNA nanoparticles for 48 hours $n=6$, naked siRNA was taken as control, and cells treated with only culture medium used as blank, $* P<0.05$ vs control and blank, respectively. (C) Live/Dead ${ }^{\circledR}$ viability/cytotoxicity experiment treated with naked siRNA and PEG-CS/siRNA nanoparticles for 48 hours, and the cells without any treatment was blank group. Data are mean $\pm S D$, and $P$-values are a result of ANOVA.

Abbreviations: PEG-CS, poly(ethylene glycol)-chitosan; siRNA, small interfering RNA 
damaged membranes to produce a bright red fluorescence. The result is shown in Figure 7C. In the blank group, nearly all cells with green fluorescence were observed, this result implied that there were a lot of live cells in the blank group after 48 hours incubating, and in the naked siRNA group, a few dead cells(red fluorescence) was appeared, suggested that naked siRNA caused 4T1 cells death slightly, while a lot of dead cells (red fluorescence) were found in the test group. This result illustrated that PEG-CS/siRNA nanoparticles can lead to cytotoxicity in tumor cells.

\section{Apoptosis assay}

The apoptotic rate was quantitatively analyzed by apoptosis assay with annexin V-FITC/propidium iodide double staining in Figure 8. The apoptosis rate was $3.85 \%$ and $5.32 \%$ in the control and naked siRNA groups, respectively, and the apoptotic rate was $16.03 \%$ in PEG-CS/siRNA nanoparticles
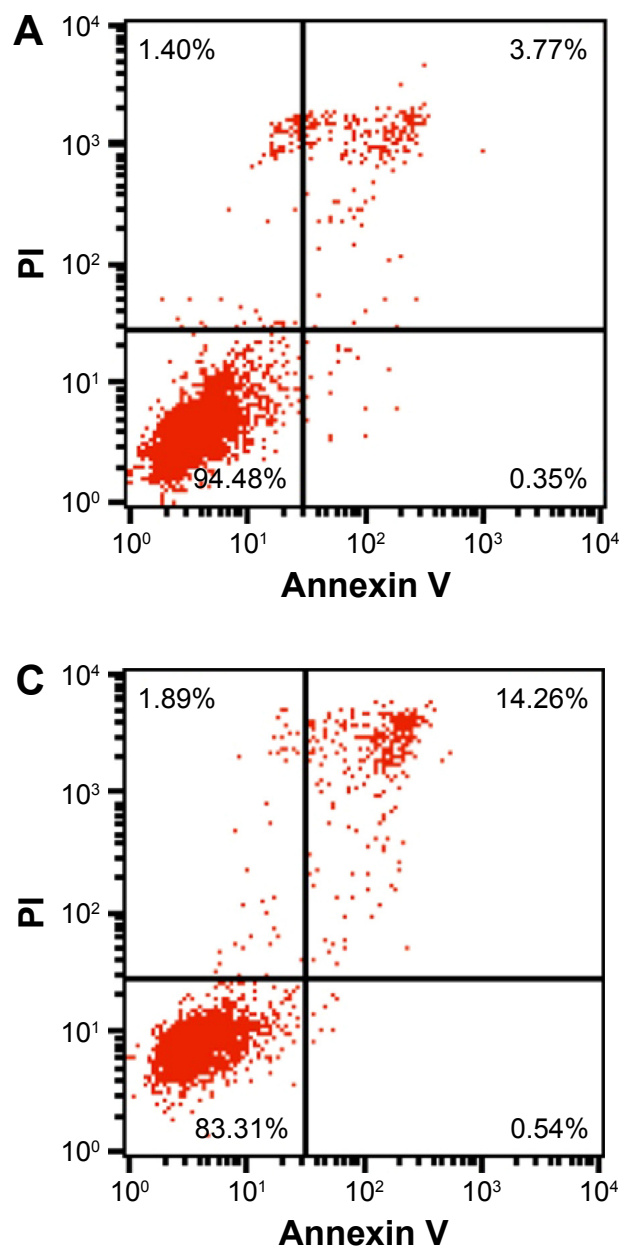

group. The apoptotic rate in PEG-CS/siRNA nanoparticles group significantly increased compared to naked siRNA and control groups, and was three times higher than the naked siRNA group. This result suggested that PEG-CS/siRNA nanoparticles induced apoptosis of tumor cells effectively.

\section{Cellular uptake}

To further investigate the PEG-CS/siRNA nanoparticles cell uptake situation, supporting flow cytometric analyses and confocal laser scanning microscopy experiments were conducted. The uptake process was evaluated using flow cytometry seen in Figure 9A. After 4 hours of incubation with PEG-CS/siRNA nanoparticles, the fluorescence peaks shifted to the right and presented a shoulder, which suggested a higher uptake of these nanoparticles. However, this was not observed in the naked siRNA group. The fluorescence peaks of the naked siRNA group were at the same position as the blank
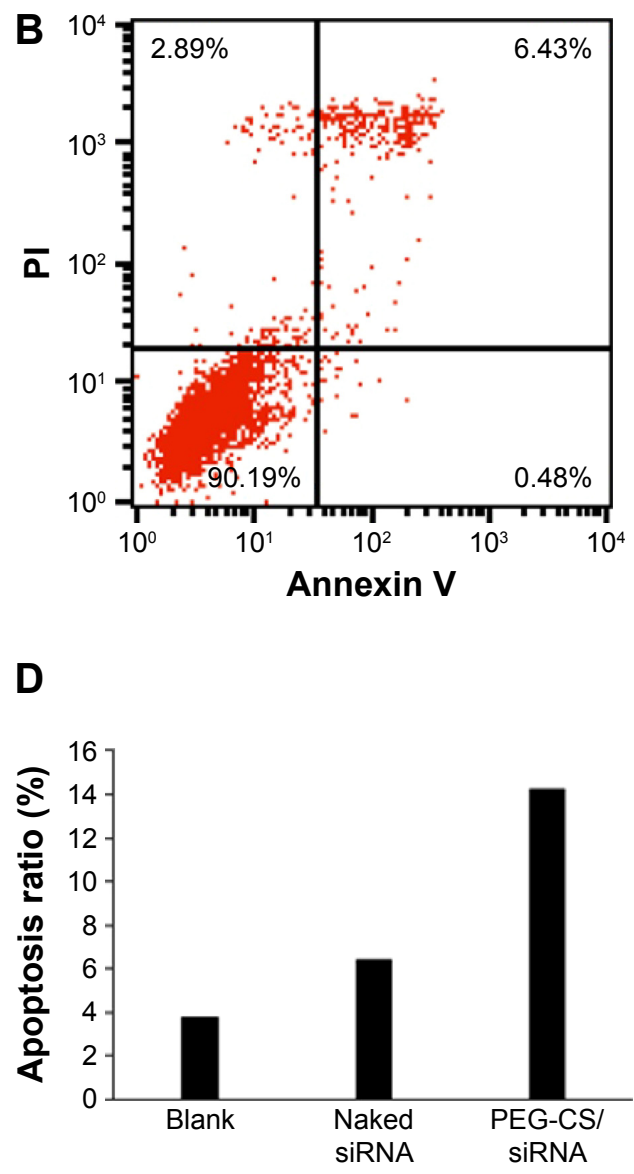

Figure 8 Apoptosis assay of 4TI cells treated with culture medium, naked siRNA, and PEG-CS/siRNA nanoparticles.

Notes: (A) Cells without any treatment were used as blank. (B) Cells treated with naked siRNA as negative control. (C) Cells treated with PEG-CS/siRNA nanoparticles. (D) Apoptosis ratio of blank, naked siRNA, and PEG-CS/siRNA nanoparticles.

Abbreviations: PEG-CS, poly(ethylene glycol)-chitosan; siRNA, small interfering RNA. 

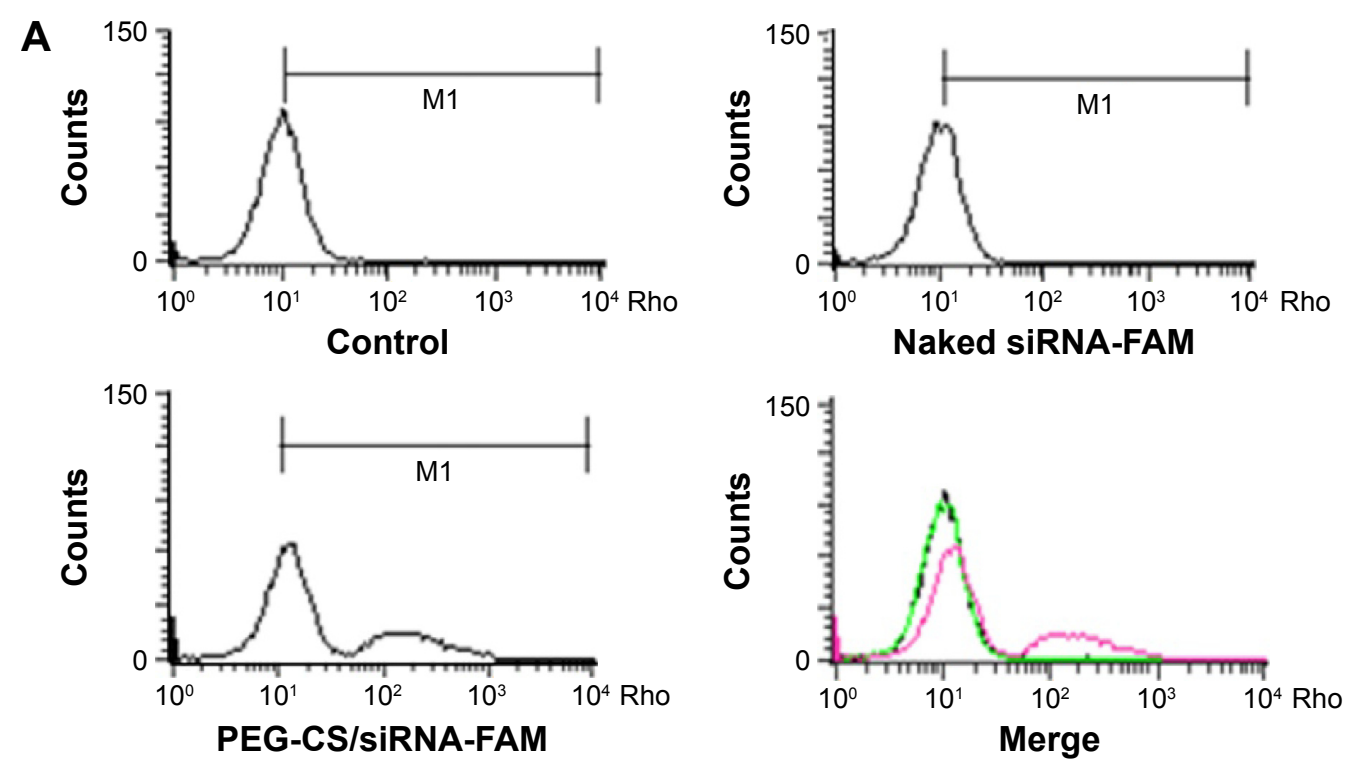

B
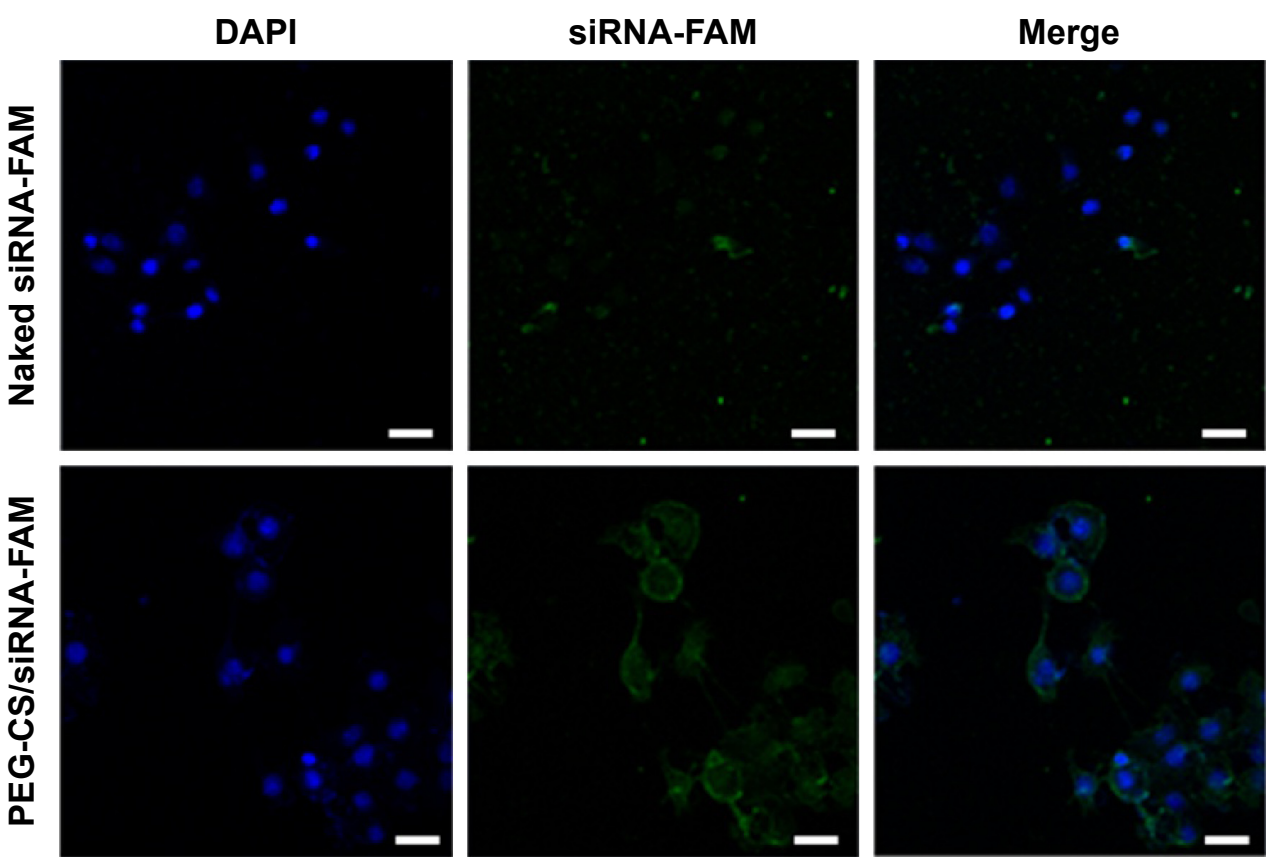

Figure 9 Cellular uptake of 4TI cells treated with nanoparticles.

Notes: (A) Flow cytometric analyses of cells treated with culture medium (control), naked siRNA-FAM, and PEG-CS/siRNA-FAM nanoparticles for 4 hours, in the merge picture: Black (control), green (naked siRNA-FAM), pink (PEG-CS/siRNA-FAM). (B) CLSM images of 4TI cells incubated with naked siRNA-FAM and PEG-CS/siRNA-FAM nanoparticles for 4 hours. The scale bar is $20 \mu \mathrm{m}$.

Abbreviations: CLSM, confocal laser scanning microscopic; PEG-CS, poly(ethylene glycol)-chitosan; siRNA, small interfering RNA; siRNA-FAM, FAM-labeled siRNA.

group. This result indicated that a small dosage of siRNA was internalized in the naked siRNA and blank groups.

The cellular uptake of the PEG-CS /siRNA nanoparticles was observed in 4T1 cells using confocal laser scanning microscopy, and the result is shown in Figure 9B. After 4 hours of incubation, the naked siRNA group showed vacant fluorescence, which indicated extremely low cellular uptake of naked siRNA, while siRNA encapsulated in the PEG-CS polymer was readily detectable in the $4 \mathrm{~T} 1$ cells.
Distinct green spots were observed in the PEG-CS/siRNA nanoparticles group, and the merged images clearly showed PEG-CS/siRNA nanoparticles in the cytoplasm. This result is consistent with flow cytometric analyses.

\section{In vivo antitumor effects of PEG-CS/ siRNA nanoparticles}

The antitumor activity of the PEG-CS/siRNA nanoparticles in vivo was evaluated in tumor-bearing $\mathrm{BALB} / \mathrm{c}$ mice model. 
After 15 days of inoculation with 4T1 cells, the average tumor volume reached was around $100 \mathrm{~mm}^{3}$. The mice were randomly divided into three groups and administered saline (blank group), naked siRNA (negative group), and PEG-CS/ siRNA nanoparticles (test group). Tumor volumes and the body weights of mice were recorded for each treatment group every other day. The mice treated with saline and naked siRNA did not show any therapeutic effect, as expected, indicating that the antitumor effect of naked siRNA was negligible. In contrast, the growth of subcutaneous tumor volumes was significantly inhibited when treated with PEG-CS/siRNA nanoparticles, as shown in Figure 10A. Among the three groups, the tumor tissues of the mice treated with PEG-CS/ siRNA nanoparticles hardly grew compared to others. A similar phenomenon had been observed by others. ${ }^{34}$ Mice were sacrificed at the fourth day after the last administration, and the tumors were isolated and weighed. The results showed that tumor weight in the test group was significantly lower than those of the naked siRNA and saline groups (Figure 10B). As shown in the Figure 10C, the tumor volume in saline group, naked siRNA group and PEG-CS/siRNA group displayed an obvious difference, and the average tumor volume in PEG-CS/siRNA group was significantly smaller than other two groups. Based on the results, we concluded that PEG-CS/ siRNA nanoparticles showed great potential in inhibiting tumor growth of 4T1-bearing mouse models. ${ }^{35,36}$

As we all know, 4T1 cells proved to be highly metastatic even at an early stage, ${ }^{37}$ so we studied the tumor metastasis of mice in the three groups by IVIS $^{\circledR}$ SPECTRUM CT in vivo imaging system. As shown in Figure 11A, obvious shift phenomenon of fluorescence area was observed in the saline and naked siRNA group, some even transferred to the brain, while the fluorescence area was smaller in test group. This suggested that PEG-CS/siRNA nanoparticles can control tumor cell metastasis effectively. Since breast cancer primarily metastasizes to the lungs, in this study, we focused mainly on the lung metastasis caused by primary breast cancer. The mice were sacrificed and lungs collected and fixed with Bouin solution, as shown in Figure 11B. There were many white nodules on the surface of the lung lobes in both the saline and naked siRNA groups, and the appearance of nodules characterized tumor metastasis. This result
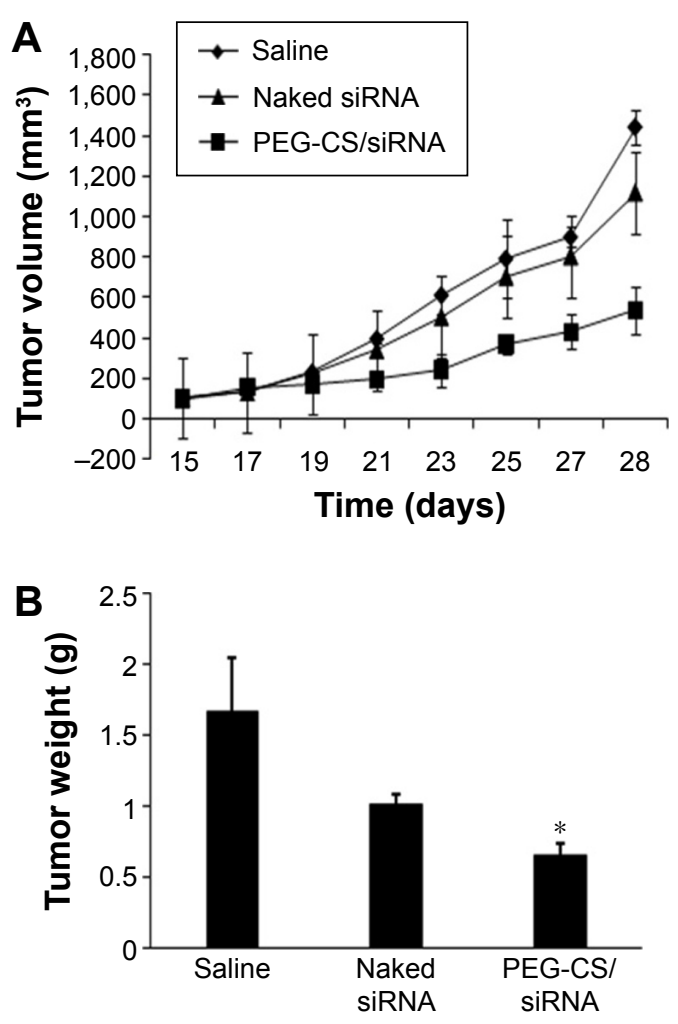

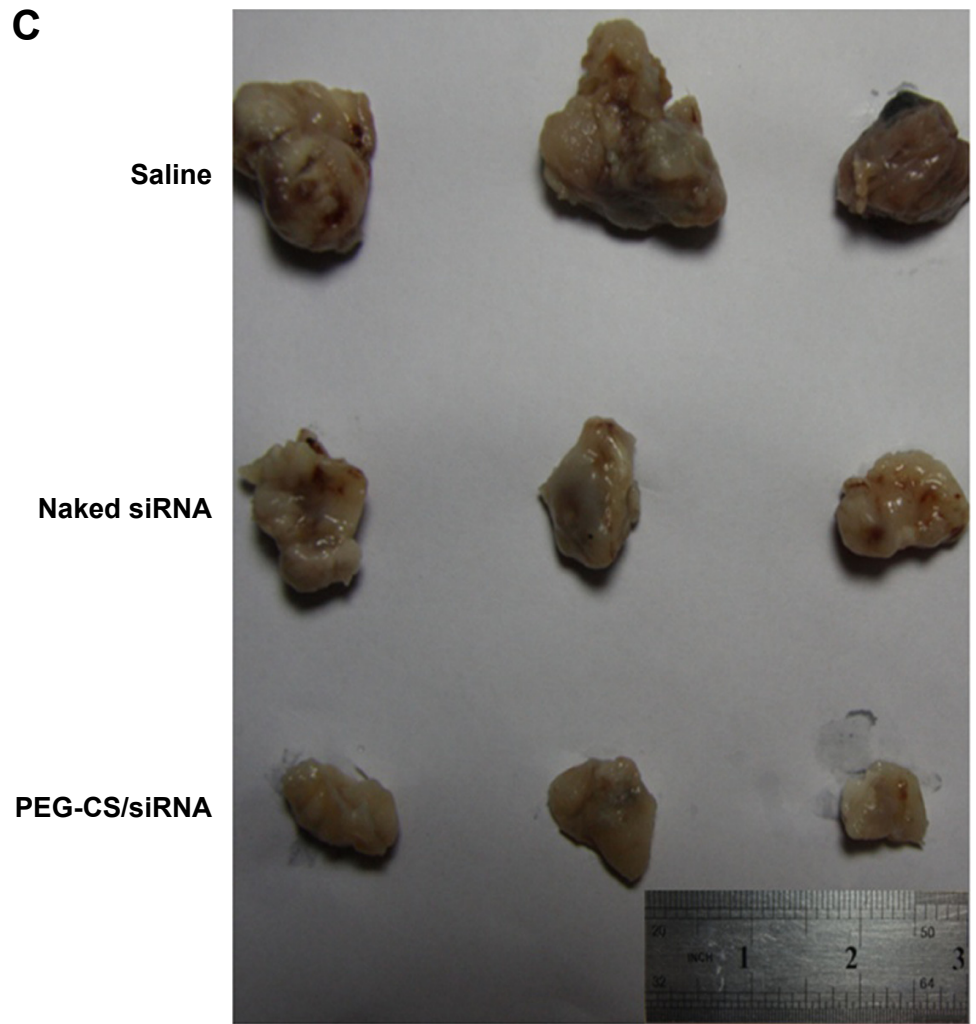

Figure 10 In vivo antitumor effect on 4TI-bearing breast cancer mice model.

Notes: (A) Tumor volume of mice treated with saline, naked siRNA, and PEG-CS/siRNA nanoparticles. (B) Tumor weight of mice treated with saline, naked siRNA, and PEGCS/siRNA nanoparticles, ${ }^{*} P<0.05$ vs saline and naked siRNA, respectively. (C) Isolated tumor tissue of mice treated with saline, naked siRNA, and PEG-CS/siRNA nanoparticles. Data are mean $\pm S D$, and $P$-values are a result of ANOVA.

Abbreviations: PEG-CS, poly(ethylene glycol)-chitosan; siRNA, small interfering RNA. 
A
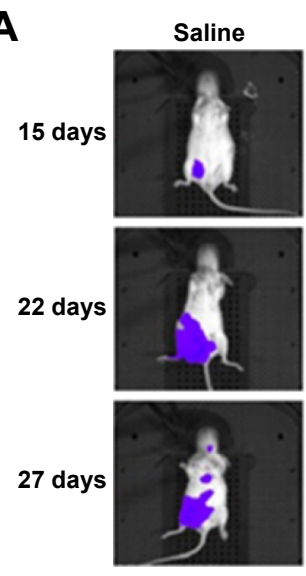

Naked siRNA
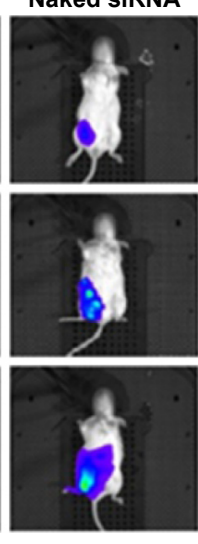

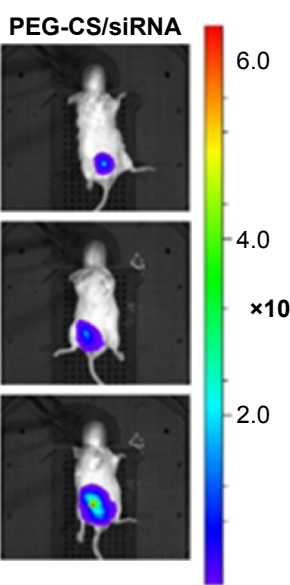

B
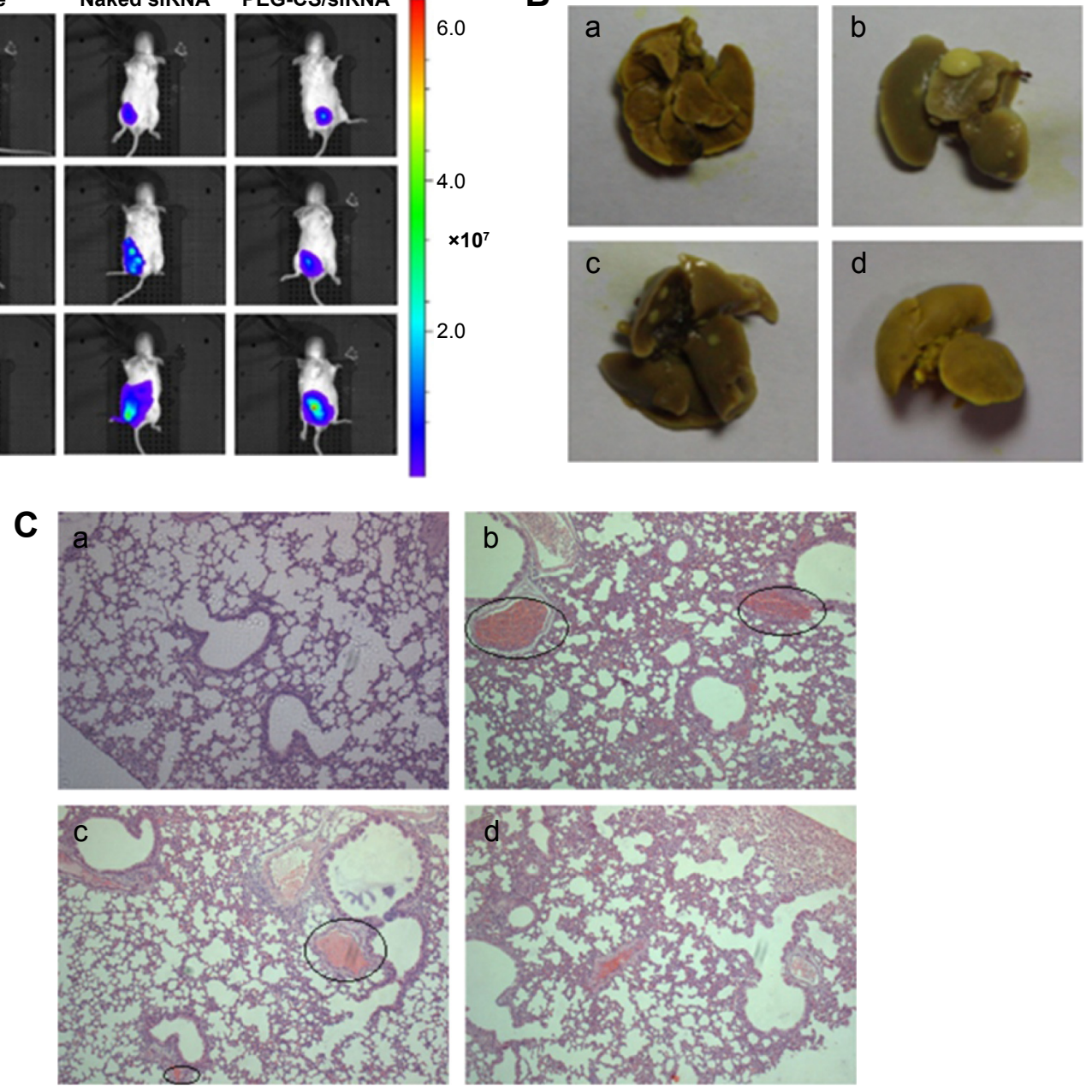

Figure I I In vivo antitumor metastatic effect on 4TI-bearing breast cancer mice model.

Notes: (A) Tumor metastatic situation was observed by bioluminescence at I 5 days, 22 days, and 27 days, respectively. (B) The lung tissue photos of 4 TI-bearing mice respectively treated with saline (b), naked siRNA (c) and PEG-CS/siRNA nanoparticles (d), lung tissue of normal mice was taken as control (a). (C) H\&E stained lung section of 4TI-bearing mice treated with saline (b), naked siRNA (c) and PEG-CS/siRNA nanoparticles (d), lung tissue of normal mice was taken as control (a). Circled areas show the metastatic areas. Abbreviations: H\&E, hematoxylin and eosin; PEG-CS, polyethylene glycol-chitosan; siRNA, small interfering RNA.

implied that lung metastasis had occurred in mice in these two groups. The surface of the lungs in the test group was smooth and almost invisible nodules were observed, which illustrated that the test group was free from lung metastasis. Additionally, the fixed lung tissues were stained with hematoxylin and eosin for histopathological examination. The results of lung histopathological examination are displayed in Figure 11C. The pathological slices from the healthy mice showed clear lung structure and alveolar septum. However, many metastatic regions were found on the pathological slices of the naked siRNA and saline group. This result suggested the occurrence of tumor metastasis in these two groups. Spots of metastatic foci were found in the pathological slices of lung tissues in the test group, which suggested that PEG-CS/siRNA nanoparticles inhibit tumor metastasis effectively. ${ }^{38,39}$

\section{Conclusion}

In this study, PEG-CS polymer as siRNA delivery carrier was synthesized successfully, which could encapsulate siRNA efficiently. PEG-CS/siRNA nanoparticles were conveniently prepared via a single-step ionic gelation method with a small size and suitable blood serum stability. Flow cytometry and confocal laser scanning microscopy results illustrated that PEG-CS/siRNA nanoparticles can be uptaken by $4 \mathrm{~T} 1$ cancer cell effectively, and MTT result showed that the antiproliferation effect of PEG-CS/siRNA nanoparticles on 4T1 cancer cells was significant. The apoptosis assay further illustrated good antitumor effect of the nanoparticles. Furthermore, the PEG-CS/siRNA nanoparticles were able to inhibit tumor growth in the $4 \mathrm{~T} 1$ tumor model by silencing the survivin gene. This delivery system needed to be further perfected to increase its therapeutic effect and reduce its adverse effect. 


\section{Acknowledgments}

This study was supported by the Beijing Natural Science Foundation (2141004), Peking Union Medical College graduate student innovation fund (500101102) and Basic Research Special Foundation for Central Public Service Research Institutes (2014ZD02).

\section{Disclosure}

The authors report no conflicts of interest in this work.

\section{References}

1. Xia YQ, Tian J, Chen XY, et al. Effect of surface properties on liposomal siRNA delivery. Biomaterials. 2016;79:56-68.

2. Zhang J, Li X, Huang L, et al. Non-viral nanocarriers for siRNA delivery in breast cancer. J Control Release. 2014;190:440-450.

3. Maines F, Caffo O, Veccia A, et al. Sequencing new agents after docetaxel in patients with metastatic castration-resistant prostate cancer. Crit Rev Oncol Hematol. 2015;96(3):498-506.

4. Jiang K, Li J, Yin JP, et al. Targeted delivery of CXCR4-siRNA by scFv for HER $2^{+}$breast cancer therapy. Biomaterials. 2015;59:77-87.

5. Chen ZH, Yu T, Zhou BF, et al. Mg(II)-Catechin nanoparticles delivering siRNA targeting EIF5A2 inhibit bladder cancer cell growth in vitro and in vivo. Biomaterials. 2016;81:125-134.

6. Chen YJ, Gu HC, Zhang DS, Li F, Liu T, Xia W. Highly effective inhibition of lung cancer growth and metastasis by systemic delivery of siRNA via multimodal mesoporous silica-based nanocarrier. Biomaterials. 2014;35(38):10058-10069.

7. Li TS, Yawata T, Honke K. Efficient siRNA delivery and tumor accumulation mediated by ionically cross-linked folic acid-poly(ethylene glycol)-chitosan oligosaccharide lactate nanoparticles: For the potential targeted ovarian cancer gene therapy. Eur J Pharm Sci. 2014; 52:48-61.

8. Fiorentini $\mathrm{C}$, Bodei $\mathrm{S}$, Bedussi $\mathrm{F}$, et al. GPNMB/OA protein increases the invasiveness of human metastatic prostate cancer cell lines DU145 and PC3 through MMP-2 and MMP-9 activity. Exp Cell Res. 2014; 323(1):100-111

9. Ozpolat B, Sood AK, Lopez-Berestein G. Liposomal siRNA nanocarriers for cancer therapy. Adv Drug Deliver Rev. 2014;66:110-116.

10. Xu CF, Wang J. Delivery systems for siRNA drug development in cancer therapy. Asian J Pharm Sci. 2015;10:1-12.

11. Ran R, Liu YY, Gao HL, et al. PEGylated hyaluronic acid-modified liposomal delivery system with anti- $\gamma$-glutamylcyclotransferase siRNA for drug-resistant MCF-7 breast cancer therapy. J Pharm Sci. 2015;104: 476-484.

12. Suzuki Y, Hyodo K, Tanaka Y, Ishihara H. siRNA-lipid nanoparticles with long-term storage stability facilitate potent gene-silencing in vivo. J Control Release. 2015;220 part A:44-50.

13. Gomes MJ, Martins S, Sarmento B. siRNA as a tool to improve the treatment of brain diseases: Mechanism, targets and delivery. Ageing Res Rev. 2015;21:43-54.

14. Ran R, Liu YY, Gao HL, et al. Enhanced gene delivery efficiency of cationic liposomes coated with PEGylated hyaluronic acid for anti $P$-glycoprotein siRNA: A potential candidate for overcoming multidrug resistance. Int J Pharm. 2014;477(1-2):590-600.

15. He BW, Wang YT, Shao NM, Chang H, Cheng Y. Polymers modified with double-tailed fluorous compounds for efficient DNA and siRNA delivery. Acta Biomater. 2015;022:111-119.

16. Frede A, Neuhaus B, Klopfleisch R, et al. Colonic gene silencing using siRNA-loaded calcium phosphate/PLGA nanoparticles ameliorates intestinal inflammation in vivo. $J$ Control Release. 2016;222:86-96.
17. Ganas C, Weiß A, Nazarenus M, et al. Biodegradable capsules as nonviral vectors for in vitro delivery of PEI/siRNA polyplexes for efficient gene silencing. J Control Release. 2014;196:132-138.

18. Misra R, Das M, Sahoo BS, Sahoo SK. Reversal of multidrug resistance in vitro by co-delivery of MDR1 targeting siRNA and doxorubicin using a novel cationic poly(lactide-co-glycolide) nanoformulation. Int J Pharm. 2014;475(1-2):372-384.

19. Zheng N, Song ZY, Liu Y, et al. Redox-responsive, reversiblycrosslinked thiolated cationic helical polypeptides for efficient siRNA encapsulation and delivery. J Control Release. 2015;205:231-239.

20. Zhong J, Huang HL, Li J, et al. Development of hybrid-type modified chitosan derivative nanoparticles for the intracellular delivery of midkine-siRNA in hepatocellular carcinoma cells. Hepatobiliary Pancreat Dis Int. 2015;14(1):82-89.

21. Mao SR, Sun W, Kissel T. Chitosan-based formulations for delivery of DNA and siRNA. Adv Drug Deliver Rev. 2010;62(1):12-27.

22. Park S, Jeong EJ, Lee J, Rhim T, Lee SK, Lee KY. Preparation and characterization of nonaarginine-modified chitosan nanoparticles for siRNA delivery. Carbohyd Polym. 2013;92(1):57-62.

23. Sharma K, Somavarapu S, Colombani A, Govind N, Taylor KM. Nebulised siRNA encapsulated crosslinked chitosan nanoparticles for pulmonary delivery. Int J Pharm. 2013;455:241-247.

24. Guţoaia A, Schuster L, Margutti S, et al. Fine-tuned PEGylation of chitosan to maintain optimal siRNA-nanoplex bioactivity. Carbohyd Polym. 2016;143:25-34.

25. Zheng JN, Xie HG, Yu WT, et al. Chitosan-g-MPEG-modified alginate/ chitosan hydrogel microcapsules: A quantitative study of the effect of polymer architecture on the resistance to protein adsorption. Langmuir. 2010;26:17156-17164.

26. Malhotra M, Tomaro-Duchesneau C, Prakash S. Synthesis of TAT peptide-tagged PEGylated chitosan nanoparticles for siRNA delivery targeting neurodegenerative diseases. Biomaterials. 2013;34(4): $1270-1280$.

27. Lee DW, Yun KS, Ban HS, Choe W, Lee SK, Lee KY. Preparation and characterization of chitosan/polyguluronate nanoparticles for siRNA delivery. J Control Release. 2009;139(2):146-152.

28. Ragelle H, Vandermeulen G, Préa VT. Chitosan-based siRNA delivery systems. J Control Release. 2013;172(1):207-218.

29. Ragelle H, Riva R, Vandermeulen G, et al. Chitosan nanoparticles for siRNA delivery: Optimizing formulation to increase stability and efficiency. J Control Release. 2014;176:54-63.

30. Hefni HHH, Azzam EM, Badr EA, et al. Synthesis, characterization and anticorrosion potentials of chitosan-g-PEG assembled on silver nanoparticles. Int J Biol Macromol. 2016;83:297-305.

31. Kim HK, Davaa E, Myung CS, Park JS. Enhanced siRNA delivery using cationic liposomes with new polyarginine-conjugated PEG-lipid. Int J Pharm. 2010;392(1-2):141-147.

32. Rajeswari A, Amalraj A, Pius A. Adsorption studies for the removal of nitrate using chitosan/PEG and chitosan/PVA polymer composites. $J$ Water Process Eng. 2016;9:123-134.

33. Preethi T, Abarna B, Rajarajeswari GR. Influence of chitosan-PEG binary template on the crystallite characteristics of sol-gel synthesized mesoporous nano-titania photocatalyst. Appl Surf Sci. 2014;317(1): 90-97.

34. Liu S, Huang W, Jin MJ, Fan B, Xia GM, Gao ZG. Inhibition of murine breast cancer growth and metastasis by survivin-targeted siRNA using disulfide cross-linked linear PEI. Eur J Pharm Sci. 2016;82: 171-182.

35. Luo $\mathrm{KW}$, Yue GGL, $\mathrm{Ko} \mathrm{CH}$, et al. In vivo and in vitro anti-tumor and anti-metastasis effects of Coriolus versicolor aqueous extract on mouse mammary 4T1 carcinoma. Phytomedicine. 2014;21(8-9): 1078-1087.

36. Yang FF, Huang W, Li YF, et al. Anti-tumor effects in mice induced by survivin-targeted siRNA delivered through polysaccharide nanoparticles. Biomaterials. 2013;34(22):5689-5699. 
37. Subramanian A, Manigandan A, Sivashankari PR SS, Sethuraman S. Development of nanotheranostics against metastatic breast cancer: A focus on the biology \& mechanistic approaches. Biotechnol Adv. 2015; 33(8):1897-1911.

38. Tang S, Yin Q, Su JH, et al. Inhibition of metastasis and growth of breast cancer by $\mathrm{pH}$-sensitive poly ( $\beta$-amino ester) nanoparticles co-delivering two siRNA and paclitaxel. Biomaterials. 2015;48:1-15.
39. Souza CM, Silva ACA, Ferraciolli CJ, et al. Combination therapy with carboplatin and thalidomide suppresses tumor growth and metastasis in 4T1 murine breast cancer model. Biomed Pharmacother. 2014; 68(1):51-57.

International Journal of Nanomedicine

\section{Publish your work in this journal}

The International Journal of Nanomedicine is an international, peerreviewed journal focusing on the application of nanotechnology in diagnostics, therapeutics, and drug delivery systems throughout the biomedical field. This journal is indexed on PubMed Central, MedLine, CAS, SciSearch $\AA$, Current Contents ${ }^{\circledR} /$ Clinical Medicine,
Journal Citation Reports/Science Edition, EMBase, Scopus and the Elsevier Bibliographic databases. The manuscript management system is completely online and includes a very quick and fair peer-review system, which is all easy to use. Visit http://www.dovepress.com/ testimonials.php to read real quotes from published authors.

Submit your manuscript here: http://www.dovepress.com/international-journal-of-nanomedicine-journal 